\title{
Positive allometry for exaggerated structures in the ceratopsian dinosaur Protoceratops andrewsi supports socio-sexual signaling
}

\author{
David W. E. Hone, Dylan Wood, and Robert J. Knell
}

\begin{abstract}
The allometry in the frill and jugal bosses of the small ornithischian dinosaur Protoceratops andrewsi are assessed. An analysis of 37 specimens, encompassing four distinct size classes of animal, shows that the frill (in both length and width) undergoes positive allometry during ontogeny, while the jugals also show a trend towards an increase in relative size. In conjunction with other data, this provides support that these features were under selection as socio-sexual dominance signals.
\end{abstract}

David W. E. Hone. School of Biological and Chemical Sciences, Queen Mary University of London, Mile End Road, E1 4NS. d.hone@qmul.ac.uk Dylan Wood. School of Biological and Chemical Sciences, Queen Mary University of London, Mile End Road, E1 4NS. d.wood@se12.qmul.ac.uk Robert J. Knell. School of Biological and Chemical Sciences, Queen Mary University of London, Mile End Road, E1 4NS. r.knell@qmul.ac.uk

Keywords: Ceratopsian; sexual selection; behavior; gregariousness

Submission: 7 August 2015. Acceptance: 10 November 2015

\section{INTRODUCTION}

Sexual selection is a powerful and near-ubiquitous evolutionary pressure (Andersson, 1994) that is responsible for much of the morphological and behavioural diversity of extant animals, which was presumably also a major evolutionary driver in the past (Knell et al., 2013a). It has been suggested by several authors (e.g., Galton, 1971; Sampson, 2001; Hone et al., 2012; Knell et al., 2013a) that many of the wide variety of ornaments and exaggerated structures on extinct animals were sexually selected, either through acting as signals in mate choice scenarios, as signals or weapons used in intrasexual contests or a combi- nation of these. Some modern signaling traits are also used in social signaling and which can be more or less related to reproduction (West-Eberhard, 1983; Kraaijeveld et al., 2004) and for some of the exaggerated traits of extinct organisms it might be better to think of explanations in terms of "socio-sexual signaling" rather than trying to be definitive about exactly how they were used (e.g., see Hone et al., 2012).

These ideas remain controversial, however, with misunderstandings over mutual sexual selection and the evolutionary biology of costly signals leading to recent exchanges in the literature regarding the validity of sexual selection as a

Hone, David W. E., Wood, Dylan, and Knell, Robert J. 2016. Positive allometry for exaggerated structures in the ceratopsian dinosaur Protoceratops andrewsi supports socio-sexual signaling. Palaeontologia Electronica 19.1.5A: 1-13 palaeo-electronica.org/content/2016/1369-sexual-selection-in-ceratopsia 


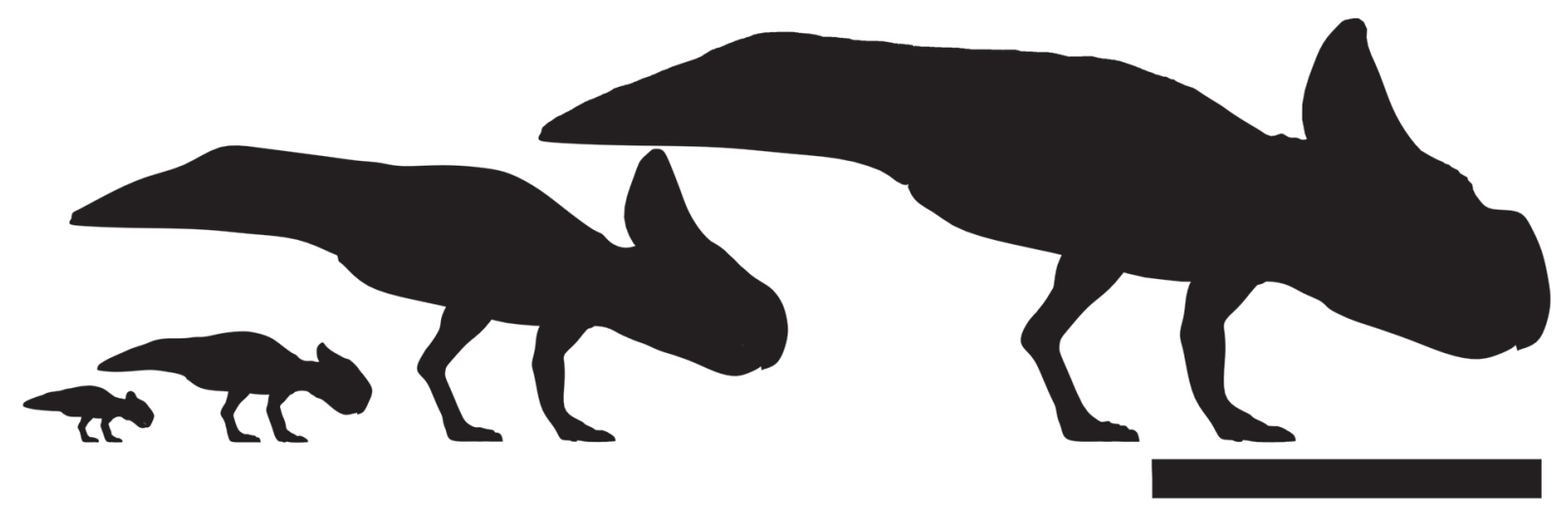

FIGURE 1. Size categories of specimens of Protoceratops andrewsi used in this study. Right to left: young juvenile, juvenile, subadult, adult. Scale bar is $1 \mathrm{~m}$. Image modified from Hone et al. (2014a), original illustration by David Maas.

hypothesis to explain exaggerated structures present in extinct animals (e.g., Padian and Horner, 2011a, b, 2013, 2014; Knell and Sampson, 2011; Hone et al., 2012; Hone and Naish, 2013; Knell et al., 2013a, b; Borkovic and Russell, 2014). The fundamental problem with trying to understand the biology of extinct organisms is that we cannot observe their behaviour directly and thus it is difficult to assess (Hone and Faulkes, 2014). As a consequence we have to fall back on more indirect assessments of whether a trait evolved through sexual selection, one of which is the rate of change of the traits in question during ontogeny (e.g., Tomkins et al., 2010; Knell et al., 2013a).

It has been acknowledged for some years now that one feature of many sexually selected traits is positive allometry - a slope greater than 1 when the log trait size is regressed against log body size (e.g., Petrie, 1992; Simmons and Tomkins, 1996; Bonduriansky and Day, 2003; Fromhage and Kokko, 2014). This translates to an exponent with a value greater than 1 in the basic allometric equation $y=a x^{b}$ where $y$ is the trait size and $x$ is the body size of the organism in question. This positive allometry means that the trait in question increases more than proportionally with body size, so that large animals have proportionally larger traits than smaller ones. Not all traits that are sexually selected are positively allometric (Bonduriansky, 2007) and there are a few examples of positively allometric traits that are not under sexual selection. For example, Simmons and Tomkins (1996) reported that earwig elytra show some degree of positive allometry, and Green (1992) described positive allometry for tail length in smooth newts Triturus vulgaris, but these are rare and probably mostly associated with locomotory traits. Sexually selected display traits and weapons, by contrast, are certainly very commonly positively allometric (Kodric-Brown et al., 2006). Allometric relations can be extracted from the fossil record when sufficient specimens are available, meaning that we can test hypotheses regarding the evolution of putative sexually selected traits by estimating their allometry. If a trait is shown to be positively allometric then, in the absence of a plausible alternative regarding its evolution, we can take this as evidence supporting a hypothesis of evolution via sexual selection or socio-sexual dominance signals (e.g., Knell and Fortey, 2005; Tomkins et al., 2010; Knell et al., 2013a).

The herbivorous ornithischian dinosaurs provide an important case for allometry linked to sexual or socio-sexual selection in the fossil record. Numerous members of this diverse group of extinct archosaurs possess large cranial crests or various other ornaments on their bodies including horns, frills, plates and 'helmets'. Members of the ceratopsian lineage (the 'horned dinosaurs') are excellent candidates for analysis for a number of reasons. There are numerous, well-preserved specimens including both juveniles of various sizes and adults (Figure 1), and all known members show a variety of cranial structures including horns, bosses and in particular a large frill that extends from the back of the head over the neck (Dodson et al., 2004; You and Dodson, 2004) (Figure 1). The small ceratopsian Protoceratops from the Late Cretaceous of China and Asia is especially well suited for study as it is known from a large number of specimens that include young juveniles through to large adults (Brown and Schlaikjer, 1940; Maryańska and Osmólska, 1975; You and Dodson, 2004). 
The shapes of ceratopsian skulls do change during ontogeny (Brown and Schlaikjer, 1940; Maryańska and Osmólska, 1975; Chapman, 1990; Sampson et al., 1997) but studies have been limited by the available data. Maryańska and Osmólska (1975), for example, reached five main conclusions about the ontogeny of the cranium of Bagaceratops and suggested that these also likely applied to Protoceratops (a close relative). These changes were "the relative length of the orbit decreases, the length of the snout increases slightly, the length of the frill at first increases, than [sic] appears to stop growing and its length becomes relatively shorter during the successive stages, the width of the frill increases, the width across the quadrates and jugals increases" (Maryańska and Osmólska, 1975). However, although these conclusions echoed some similar patterns observed in Protoceratops by Brown and Schlaikjer (1940), they were limited by a lack of complete specimens that spanned a broad range of ages. Similarly, Dodson (1976) assessed sexual dimorphism in Protoceratops and his analyses included allometric regressions of various measurements, but his study focused on adult or nearadult animals with only a very limited sample or younger specimens.

A large number of hypotheses have been advocated for the functions of the cranial features of ceratopsians including signaling and/or sexual selection (Farlow and Dodson, 1975), though this has in the past often been incorrectly ruled out because of a lack of apparent sexual dimorphism in many taxa (see Hone et al., 2012 for review). In at least some ceratopsians the horns were used in intraspecific combat (Farke et al., 2009) and may have been involved in interspecific combat (Happ, 2008), though they may have served additional purposes (e.g., as aposematic signals). A particularly wide range of explanations has been proposed for the functions of the ceratopsian frill including: as a temperature regulating device, as an aposematic signal, as a defence against predators and for socio-sexual dominance signals. However, in most taxa many of these can be ruled out (see Hone et al., 2012 for a review), leaving sexual or socio-sexual signaling as the most plausible current explanation for the evolution of these structures.

Here we assess the growth of the frill in Protoceratops based on a larger sample of specimens and across a range of body sizes in excess of an order of magnitude, including animals that can be assigned to four distinct size classes from young juveniles to large adults (Hone et al., 2014a). We show that both the length and width of the frill are positively allometric, suggesting a signaling function.

\section{METHODS}

Data on Protoceratops andrewsi skulls were taken from the literature and measured from published photographs of specimens. Data on larger specimens of $P$. andrewsi were taken from Dodson (1976) that focused on animals of 'subadult' and adult sizes. In his analysis of skull dimorphism, Dodson (1976) illustrated a number of major metrics of skull and frill dimensions based around landmarks of the cranium. His measure of basal skull length (variable 1 of Dodson, 1976) was taken as the standard unit of size of the skull (Dodson 1976) measured from the tip of the snout to the base of the articular in line with the ventralmost point of the lower temporal fenestra (also corresponding to the position of the foramen magnum). The length of the frill was taken as Dodson's (1976) total skull length less the basal skull length, however, where the anterior anchor could not be determined, a minimum was measured to the anterior margin of the frill fenestrae and a maximum to the posterior margin of the orbit. The width of the frill was measured as the maximum width of the frill (variable 9 of Dodson, 1976), and the width across the jugal bosses (variable 8 of Dodson, 1976) was recorded, as were the orbit length and height (variables 13 and 14 of Dodson, 1976).

Additional measurements from younger specimens were taken from (smallest to largest) Fastovsky et al. (2011), Hone et al. (2014a) and Handa et al. (2012) corresponding to young juveniles, juveniles, and subadults (Figure 1). These non-adult specimens at least all correspond to similar localities within the Djadochta Formation and can be considered part of a single population (see Hone et al., 2014a), and the material measured by Dodson, (1976) also herald from the same formation (Brown and Schlaikjer, 1940). Measurements were taken from figures in the papers and unpublished photographs by the authors. The measurements taken from these non-adult animals were made using the program ImageJ (Schneider et al., 2012) and correspond with the variables described above to allow integration of the data. However, the inclusion of very young animals with very different proportions and shapes to the skull (Figure 2) makes it difficult to ensure that some other measurements correspond properly with Dodson's (1976) landmarks.

Where images of the small specimens presented the skull only in dorsal view (e.g., very young specimens of Fastovsky et al., 2011), the 

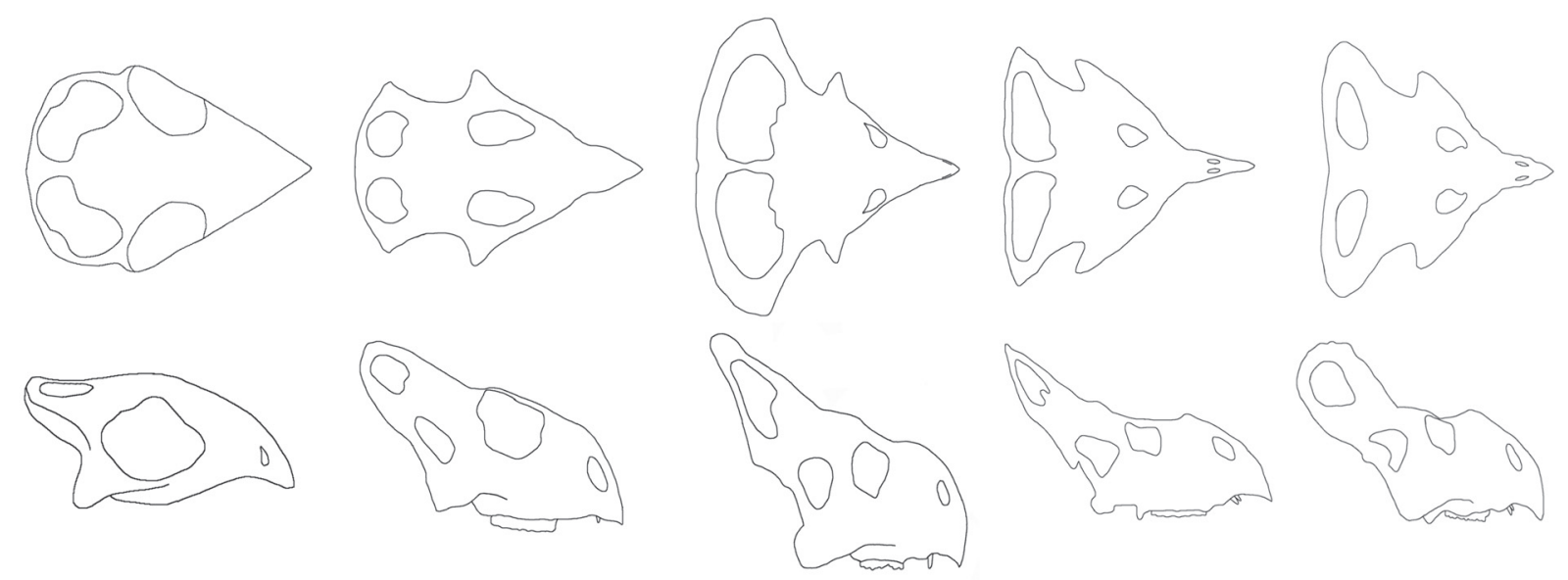

FIGURE 2. Changes in skull shape in Protoceratops andrewsi. All skulls are drawn to the same total length and are seen in dorsal view (upper row) and right lateral view (lower row). Left to right (with sources in parentheses) small juveniles (Fastovsky et al., 2011), juveniles (MPC-D 100/526), subadults (MPC-D 100534), putative 'female' morph, putative 'male' morph (both Dodson, 1976). The large fenestrae seen in the smallest animals are supratemporal fenestra and are not homologous with the frills of the fenestra in the larger animals.

basal skull length was measured in the midline of the skull from the tip of the rostrum to a point midway between the posterior margin of the orbit and the anterior margin of the fenestra in the frill (Figure 3). Similarly, additional measurements were taken for the frill of the smallest specimens. The length of the frill was taken to a point midway between the dorsoposterior margin of the orbit and the anteriomedial margin of the fenestra, but a maximum frill length and minimum frill length were also recorded, terminating at these respective points on the orbit and fenestra (Figure 3). Measurements of specimens taken from photographs may be subject to parallax error; however, as far as possible photographs were taken parallel to the long axis of the respective total skull lengths (cf Figure 3) to minimise the effects of these errors.

A total of 37 specimens were included in the analysis, although not all measurements were available for each specimen. Specimens ranged in size from a basal skull length of 23.5 to $357 \mathrm{~mm}$ (or including the frill, from 35 to $515 \mathrm{~mm}$ ) - see data in Appendix. Assessment was based on the search for positive allometry of the crests with respect to isometry of other elements (see Tomkins et al., 2010), here using basal skull length. This measure has been shown by Dodson (1976) to change isometrically with other major features of the skull suggesting it is an appropriate metric for this purpose. Although there are obvious limitations with small datasets (Brown and Vavrek, 2015), the data set used here is larger than a number of previous assessments of allometry in fossil taxa and covers a greater range of animal sizes, and thus is sufficient given the limitations of the fossil record.

Allometric slopes for the log-transformed values for frill length and width, the width across the jugal bosses and also orbit length and width were calculated using Standardised Major Axis (SMA) regressions (Warton et al., 2006; Westoby, 2006) using the smatr package (Warton et al., 2012) running in $R$ v. 3.1.2 ( $R$ Core Team, 2014). SMA is sometimes referred to as Reduced Major Axis but it has been argued that this latter term can be misleading and is, in fact, based on a mistranslation from the French (Warton et al., 2006, appendix A). Tests for deviation of the slopes from a value of 1 were carried out by calculating an $r$ test statistic in the same way as for a conventional linear regression as recommended in Warton et al. (2006).

Sexual dimorphism has been proposed to explain the frill and other cranial characteristics of P. andrewsi (see Dodson 1976). However, sexual dimorphism has recently been reassessed and rejected as a hypothesis for these characteristics (Maiorino et al., 2015) and so we analysed all available data and did not split the adults into the putative male and female morphs. This would also have reduced the amount of available data for each analysis if the sexes were treated separately.

\section{RESULTS}

Both frill length and frill width showed positive allometry in Protoceratops (Table 1, Figure 4). The width across the jugal bosses gave an allometric 


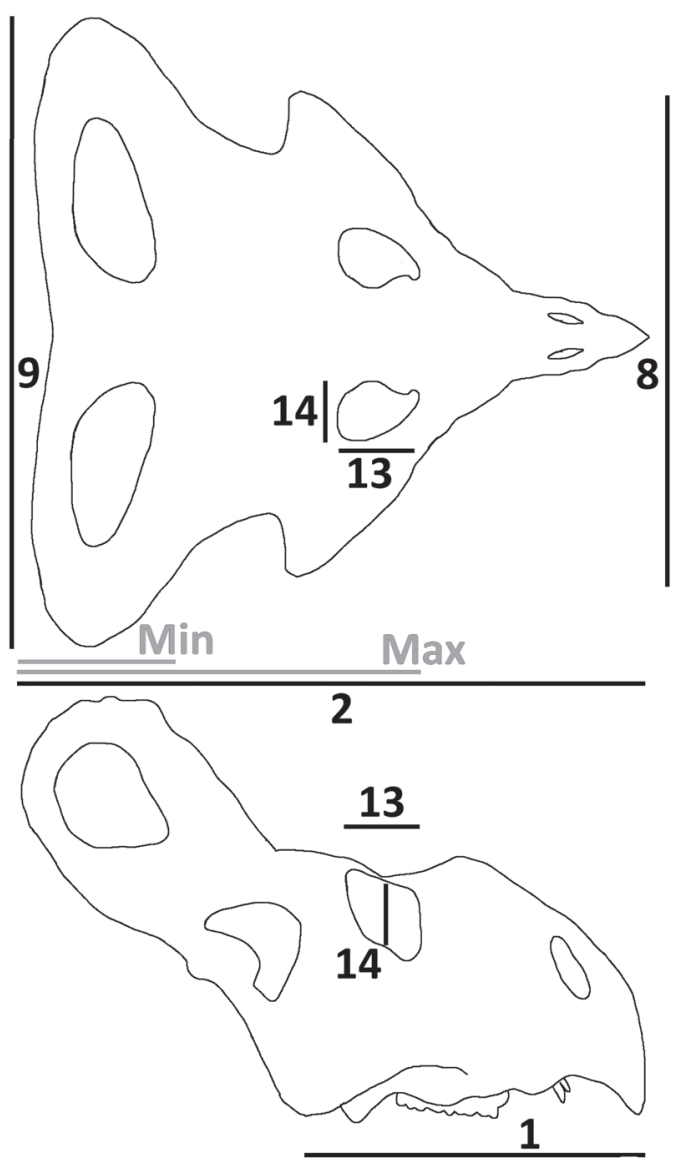

FIGURE 3. Measurements taken from skulls of Protoceratops based on an idealised adult in dorsal view (above) and lateral view (below). Black lines and numbers indicate the measurements taken according to the variable of Dodson (1976). These are: 1, basal skull length; 2 , total length (frill length is variable 2 subtracted from variable 1 ); 8 , jugal width; 9 , frill width; 13 , orbit length; 14 , orbit height. The grey lines indicate the maximum and minimum lengths of the frill as measured in juvenile animals. See text for further details.

slope that was not significantly different from 1 , although the slope was suggestive of positive allometry with confidence intervals which only just overlapped with $1(0.983-1.34)$ and a p-value of 0.078 for the test comparing the slope to isometry. In the case of frill length, this result was qualitatively unchanged when the minimum and maximum frill lengths were used as alternate measurements from the smaller specimens (maximum frill length: slope $=1.21$, minimum frill length: slope $=1.27$ ). As skull basal length increases, therefore, both the length and the width of the frill become larger relative to the rest of the skull.

By contrast with the increase in frill length and width, both orbit length and orbit height showed negative allometry, although height increased with basal skull length faster than did width, indicating that the shape of the orbits changed as the animals got larger. As can be seen from Figure 2, small Protoceratops have orbits that are longer than they are high, whereas the larger animals have orbits that are closer to being circular, with orbit length and orbit height being roughly equal in the largest specimens.

\section{DISCUSSION}

The results here provide strong evidence for the growth of the frill in Protoceratops andrewsi being greater than the overall growth of the animal by demonstrating positive allometry (Table 1). The different dimensions of the frill show different allometric slopes, demonstrating that the frill changed in shape as well as size (as the changes in frill width are slightly greater than length). The increase in length and width fits with the suggestions of both Brown and Schlaikjer (1940) and Maryańska and Osmólska (1975) although the latter noted that, in Bagaceratops at least, the frill at some point stopped increasing in length before expanding again. That cessation of growth is not seen here, though the limited number of specimens in their analysis means that this pattern could have been caused by one or a few unusual individuals. Chapman (1990) suggested that the length of the frill in Bagaceratops was close to isometry, but this is not the case here. Dodson (1976) used a different allometric regression technique to that used here, but the results should still be qualitatively comparable. Across his data, Dodson (1976) recorded a slight decrease in frill length with a slight increase in frill width for Protoceratops although in both cases the slope was below significance at $P=0.05$. However, his dataset contained only one small individual (basal skull length under $100 \mathrm{~mm}$ ) with most specimens representing subadults or adults, though it is still a rather different result to our own that shows consistent positive allometry for the frill across all skull sizes.

Furthermore, the metrics used here are a simplification of the changes that Protoceratops experiences as other patterns are clearly visible (though not directly assessed here). For example, as well as increasing in both length and width, the crest also appears to deflects upwards in adults to be steeply inclined relative to the skull roof whereas it is largely in line with the skull roof in younger animals (Figures 1,2). Although there is not a complete ontogenetic sequence available for Protoceratops, this deflection is not seen in 
TABLE 1. SMA slopes and associated statistics for frill and other skull traits from Protoceratops andrewsi.

\begin{tabular}{|l|c|c|c|c|c|}
\hline \multicolumn{1}{c}{ Measure } & \multicolumn{1}{c}{ Intercept } & \multicolumn{1}{c}{ Slope } & \multicolumn{1}{c}{ Slope Cls } & \multicolumn{1}{c}{ Test statistic } & $P$ slope $\neq 1$ \\
\hline Frill length & -1.46 & 1.23 & $1.14-1.34$ & $r=0.719,26 \mathrm{df}$ & $<0.0001$ \\
\hline Frill width & -1.21 & 1.29 & $1.19-1.41$ & $\mathrm{r}=0.827,18 \mathrm{df}$ & $<0.0001$ \\
\hline Jugal Boss width & -0561 & 1.15 & $0.983-1.34$ & $\mathrm{r}=0.403,18 \mathrm{df}$ & 0.078 \\
\hline Orbit width & 0.272 & 0.699 & $0.650-0.751$ & $\mathrm{r}=-0.877,30 \mathrm{df}$ & $<0.0001$ \\
\hline Orbit height & -0.583 & 0.843 & $0.760-0.935$ & $\mathrm{r}=-0.526,30 \mathrm{df}$ & 0.002 \\
\hline
\end{tabular}

younger specimens suggesting that it does not occur until the animals are relatively old. This change also means that the length of the frill is effectively foreshortened when measured in lateral or dorsal view (as done here cf. Dodson, 1976) rather than measuring along the actual elements of the frill themselves. Thus as the frill deflects in older individuals this measurement will underestimate the true length of the frill and the proportional growth rate is therefore likely to be greater than that calculated here. Maiorino et al. (2015) also noted the dorsal deflection of the frill during ontogeny as well as additional changes not commented on here such as the elongation of the rostrum and development of a nasal bump in larger specimens. This latter increase in the nasal bump was also noted by Brown and Schlaikjer (1940) and is effectively the same point raised by Lull and Gray (1949) who noted an increase in depth in the nasal region.

Finally, the smallest specimens have large supratemporal fenestrae that dominate the frill and almost contact the orbits, whereas in adults these fenestrae are closed and the fenestrae in the frill are limited to the posterior part of the frill (Figure 2). Other apparent changes include the elongation of the premaxillary teeth that are proportionally short in juveniles and enlarged in adults (Figures 1,2) and in the postcranium, the enlarged neural spines on the midpoint of the caudal vertebral series appear to grow taller later in ontogeny.

Interestingly the width of the skull across the jugals is here shown not to differ from isometry. This differs from what was suggested by Maryańska and Osmólska (1975), although Chapman (1990) suggested that the jugal width is isometric in Bagaceratops at least, and Dodson (1976) recorded near isometry for the jugal width among larger individuals. The result we have returned may be confounded by an overall change in the shape of the skull as we and others have measured the entire width of the skull including the jugal bosses, rather than just the bosses themselves. Additional data may confirm if this dimension is truly isometric or does demonstrate positive allometry, though if they are isometric, it would sug-
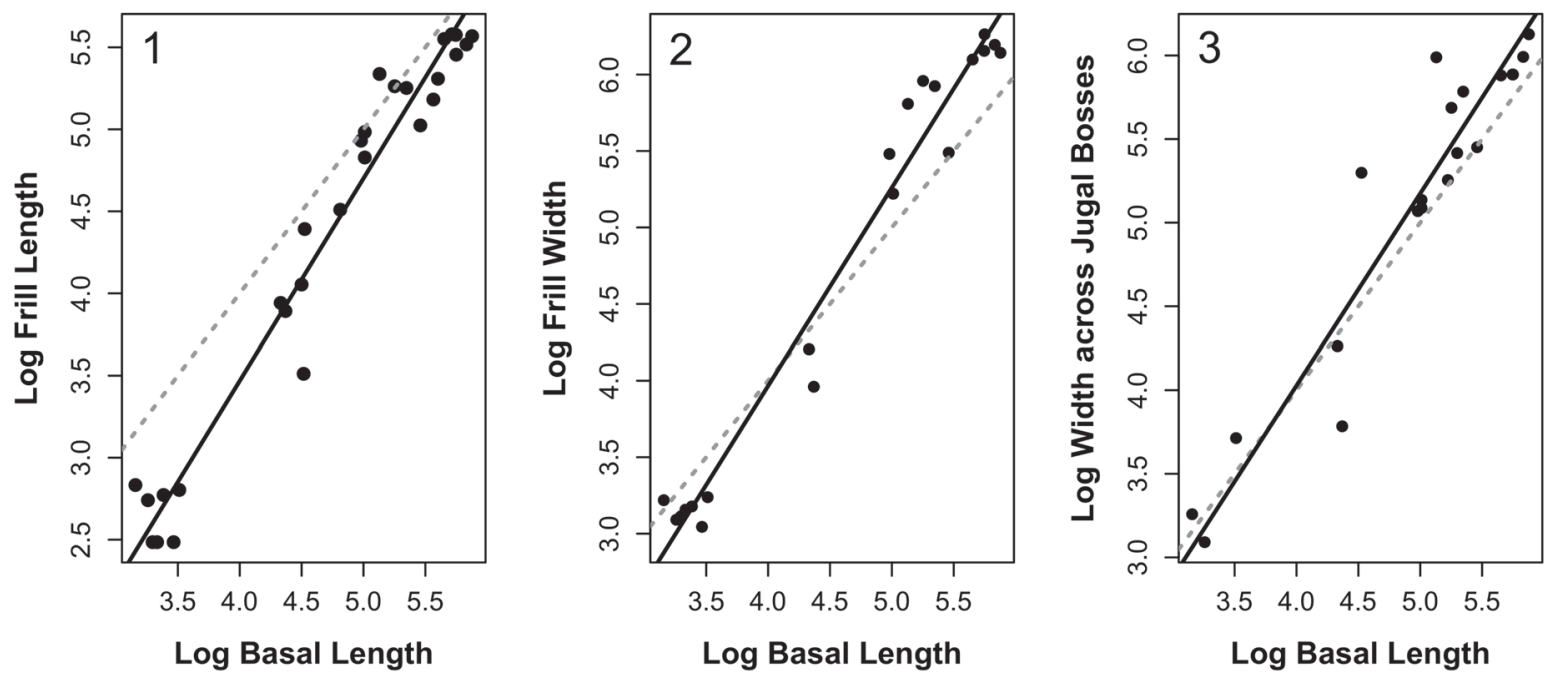

FIGURE 4. Allometric relationships for frill length (1), frill width (2) and the width across the jugal bosses (3). Solid lines show the fitted lines from SMA regression, dashed grey lines show the line of isometry (slope $=1$ and intercept $=0$ ). All measurements were originally in $\mathrm{mm}$ prior to log transformation. 
gest a functional role that does not change with ontogeny.

Although orbit shape is not directly related to crest morphology, this has been observed to change in Protoceratops (Brown and Schlaikjer, 1940; Maryańska and Osmólska, 1975; Dodson, 1976; Maiorino et al., 2015). Orbit size has been used as a metric against which other values can be scaled in assessments of ontogenetic allometry in extinct amniotes and may be isometric in at least some taxa (Tomkins et al., 2010). Maryańska and Osmólska (1975) observed a decrease in relative orbit width for Bagaceratops with Dodson (1976) demonstrating a sharp decrease in orbit height and an even greater decrease in width (his 'orbit length'). Both of these observations are consistent with the results recovered here showing a strong negative allometry for the orbit but also a change in shape given the differences in slope recovered for the two different dimensions.

The positive allometry seen in the frill demonstrates that the frill grows faster than the rest of the animal as individuals increase in size. Definitions of maturity in non-avian dinosaurs are complicated as at least some were reproductively mature before they were fully osteologically mature (e.g., Lee and Werning, 2008) and thus it is difficult to determine exact timing of changes between 'juveniles' and 'adults' (see Handa et al., 2012 and Hone et al., 2014a for discussions of age categories in Protoceratops). However, it is clear that the frill was disproportionally small in younger individuals, grew faster than the rest of the animal during ontogeny, and reached full size only in large adult specimens. Such a pattern of rapid growth combined with ontogenetic change makes socio-sexual dominance displays a strong hypothesis to explain these results (Knell et al., 2013a) as the relative sizes of the crests suggests a function in adults but not in juveniles.

If the frill acted as a socially or sexually selected signal, this would explain other observed patterns in Protoceratops. It is common for animals to exhibit multiple sexually selected traits (Omland, 1996) and this would match the potential use of the premaxillary teeth and the neural spines of the tail as additional signals. The former might have a role in signaling or even intraspecific combat, and it has been suggested by Tereschenko and Singer (2013) that the tail of Protoceratops might be well suited to being raised as a signal. As dinosaurs apparently reached sexual maturity before full adult size this may also potentially explain the isometric growth of the frill recorded by Dodson (1976) for his study of subadult and adult animals. If the subadults were sexually mature then this may correlate with a growth of the frill to reach proportional peak size at this point in order to act as a viable signal of maturity.

Species recognition has been advocated as a selective pressure to explain the presence of crests such as ceratopsian frills in various dinosaurian taxa (e.g., see Padian and Horner, 2011a, b, 2013). This has been strongly criticised as it fails to explain the observed patterns in crest distribution on taxa, or the presence of such costly signals in the fossil record that are unknown in extant taxa (e.g. see Knell and Sampson, 2011; Knell et al., 2013a, b; Hone and Naish, 2013). It is possible that the presence of these crests in adults did help individuals recognise conspecifics, but this would be a co-opted function, not the primary origin and drive behind its evolution (Hone and Naish, 2013).

As a concept, 'species recognition' may relate to either correct mate identification or the more general ability of individuals to recognise conspecifics such as in relation to forming and maintaining a group (see Hone and Naish, 2013). In the case of the latter aspect, this is not supported for $P$. andrewsi based on the known behavior of these animals. Although many specimens of $P$. andrewsi are known from isolated remains, there are now size-segregated aggregations of this species at multiple sizes, which likely represent different age classes (Hone et al., 2014a). As such, if the frill was important to help identify conspecifics in aggregations, then it would be selected to be present in even young animals, or alternatively if the frill as seen in juveniles was a sufficient signal, there would be no need for it to increase in size and change shape in adults. In terms of mate recognition, as noted for other ceratopsians (Hone and Naish, 2013), the fact that the frill continued to change shape after sexual maturity would potentially confound signals. In addition, neither aspect of species recognition explains the strong similarity of frill (and indeed general cranial morphology) of $P$. andrewsi to other sympatric species of Protoceratops or other protoceratopsids. Selection for recognition would drive species to produce more disparate, rather than highly similar forms (Hone and Naish, 2013).

Similar patterns of positive allometric growth of cranial crests during ontogeny are also seen in other ornithischian dinosaurs. Sampson et al. (1997) stated that both the horns and frills of the centrosaurine ceratopsian dinosaurs showed positive allometry during growth (and these features 


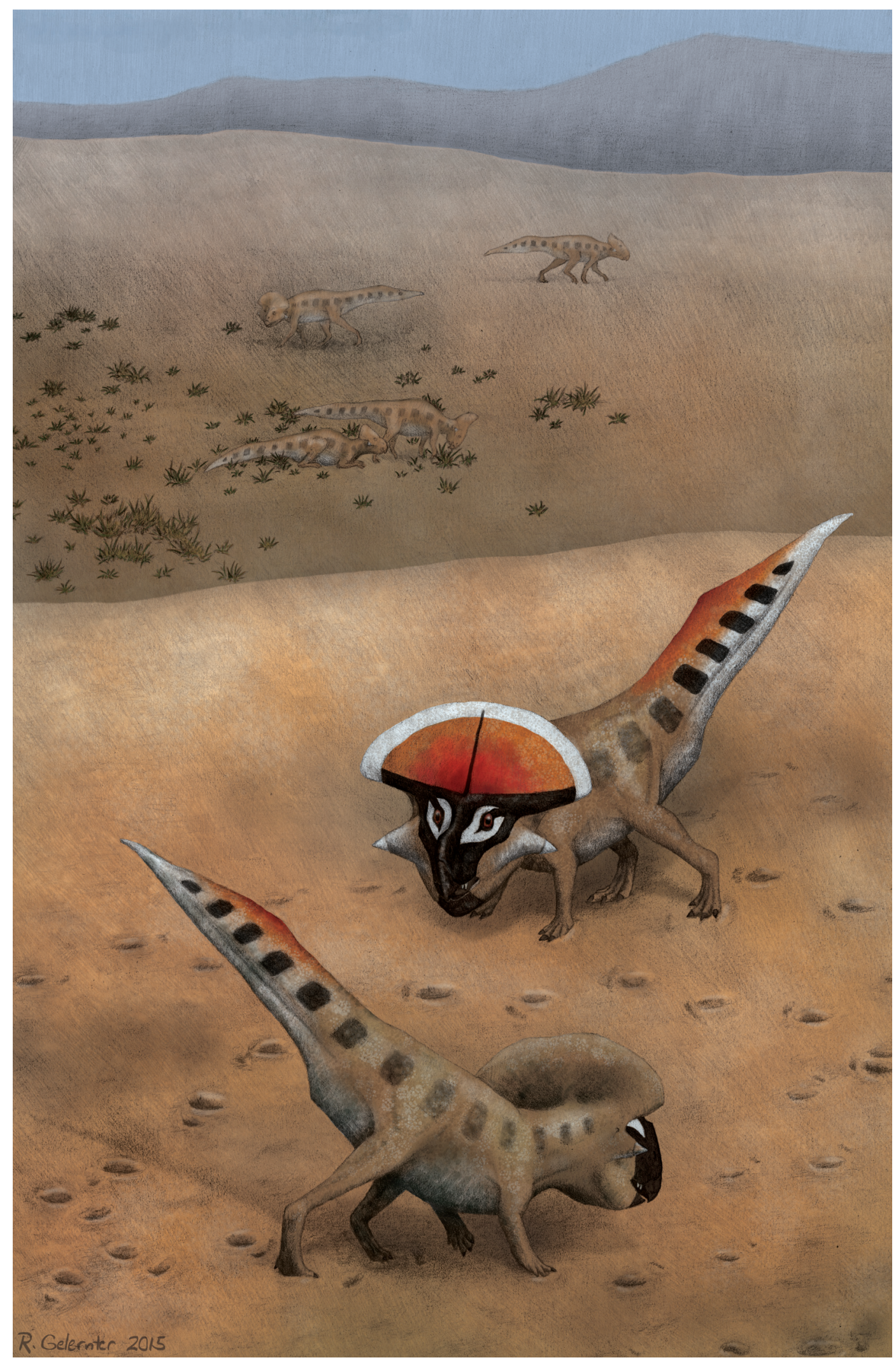

FIGURE 5. Life restoration of adult Protoceratops andrewsi (foreground) engaging in speculative display postures, an activity in which non-mature animals (background) do not take part. Artwork by Rebecca Gelernter, who retains the copyright on this image - used with permission. 
also change in shape as they grow), though this was stated without a formal analysis owing to a lack of complete cranial material. Similarly, Mallon et al. (in press) described a specimen of Arrhinoceratops at circa $70 \%$ of adult size but where the frill was less than $50 \%$ of that of the adult, and the horns $30 \%$ of that of the adult (their figure 10), implying relatively rapid growth late in ontogeny. Evans (2010) also found strong positive allometry in the development of the crests of a number of hadrosaur genera with increases in size and changes in shape relatively late in ontogeny and juveniles exhibiting no, or only incipient, crests. Although not discussed in terms of possible functions by Evans (2010), the implications are similar to those discussed here, and it is possible to infer that these were selected for socio-sexual dominance.

Some hadrosaur and ceratopsian mass mortality sites do show size-sorted groups and include the presence of adult-only groups (e.g., see Hone et al., 2014b) or non-adult only groups (e.g., see Lehman, 2007; Lauters et al., 2008). However, others show groups of multiple different sizes and include both juveniles (or at least subadults) and adults together (e.g., see Sampson et al., 1997; Brinkman, 2014), a pattern also seen in some trackways (Lockley, 1991). For Protoceratops, however, the presence of mixed-age groups, as well as clusters of adults only and juveniles only, suggests that the enlarged cranial crests of various ornithischians were not linked to herd coherency (in the sense of correct identification of conspecifics). If they were, then such features would be present in both juveniles and adults and to the same degree, as this would be beneficial to both age groups in mixed herds, or to groups of all juveniles. Instead, again the positive allometry and the presence in adults but not younger animals strongly implies this is a function that benefits only adult animals, and thus socio-sexual signals are a strong candidate to explain this pattern of growth.

Our results do not rule out additional functions of such crests they might have had beyond sexual and social dominance signals, although some hypotheses can be excluded. The ceratopsian frill would have provided little protection as armour against animals like large tyrannosaurs that lived alongside $P$. andrewsi (see Jerzykiewicz et al., 1993) and that could bite into or through much thicker and stronger bones (see Hone and Rauhut, 2010). A large frill may act as an aposematic signal to heterospecifics (especially predators), though as juvenile dinosaurs were generally more vulnerable to predators than adults (Hone and Rauhut, 2010) then the small frill size in juveniles suggests limited value. Large bodied (multi-ton) tyrannosaurs may have been little deterred by such signals and unlike many other ceratopsians, Protoceratops lacked large horns with which it could engage potential predators (cf. Happ, 2008). This would make a signal effectively a false one, and such signals typically only operate if the bearer is rare (Mallett and Joron, 1999) when in fact Protoceratops is generally the most common large tetrapod in its environment (based on the huge numbers of recovered specimens). If ceratopsians generally used their frills as aposematic signals, then we might predict convergence of form through Mullerian mimicry among those that were sympatric, and perhaps even convergent Batesian mimicry from rarer taxa.

\section{CONCLUSIONS}

Based on the available data it seems likely that the frill, and perhaps the jugal bosses, of Protoceratops andrewsi were features that functioned in signaling (Figure 5). The absence of support for alternate hypotheses combined with the positive allometry shown here across a wide range of individuals suggests a feature that functioned only in adults and a socio-sexual dominance signal is the best available candidate.

Despite extensive debate in recent years as to the functions of these and similar structures in various archosaur and other lineages, relatively little hypothesis testing has been carried out (e.g., see Tomkins et al., 2010). These results therefore provide an important step in assessing the function of such features in the fossil record and provide confirmation that these likely evolved as a result of pressures favouring socio-sexual dominance signals.

\section{ACKNOWLEDGEMENTS}

We thank P. Dodson for making his dataset accessible and $\mathrm{N}$. Handa for providing supporting photographs. Our thanks to two anonymous referees and the editor for the suggestions and assistance in taking this paper to publication.

\section{REFERENCES}

Andersson, M. 1994. Sexual Selection. Princeton University Press, Princeton.

Bonduriansky, R. 2007. Sexual selection and allometry: a critical reappraisal of the evidence and ideas. Evolution, 61:838-849. 
Bonduriansky R. and Day, T. 2003. The evolution of static allometry in sexually selected traits. Evolution, 57:2450-2458.

Borkovic, B. and Russell, A. 2014. Sexual selection according to Darwin: a response to Padian and Horner's interpretation. Comptes Rendus Palevol, 13:701-707.

Brinkman, D.B. 2014. The size-frequency distribution of hadrosaurs from the Dinosaur Park Formation of Alberta, Canada, p. 416-421. In Eberth, D.A. and Evans, D.C. (eds.), Hadrosaurs. Indiana University Press, Bloomington.

Brown, B. and Schlaikjer, E.M. 1940. The structure and relationships of Protoceratops. Annals of the New York Academy of Sciences, 40:133-266.

Brown, C.M. and Vavrek, M.J. 2015. Small sample sizes in the study of ontogenetic allometry; implications for palaeobiology. PeerJ, 3:e818.

Chapman, R.E. 1990. Shape analysis in the study of dinosaur morphology, p. 21-42. In Carpenter, K. and Currie, P. (eds.), Dinosaur Systematics: Approaches and Perspectives. Cambridge University Press, New York.

Dodson, P. 1976. Quantitative aspects of relative growth and sexual dimorphism in Protoceratops. Journal of Paleontology, 50:929-940.

Dodson, P., Forster, C.A., and Sampson, S.D. 2004. Ceratopsidae, p. 494-513. In Weishampel, D.B., Dodson, P., and Osmólska, H. (eds.), The Dinosauria. University of California Press, Berkley.

Evans, D.C. 2010. Cranial anatomy and systematics of Hypacrosaurus altispinus, and a comparative analysis of skull growth in lambeosaurine hadrosaurids (Dinosauria: Ornithischia). Zoological Journal of the Linnean Society, 159:398-434.

Farke, A.A., Wolff, E.D.S., and Tanke, D.H. 2009. Evidence of combat in Triceratops. PLoS ONE, 4:e4252.

Farlow, J.O. and Dodson, P. 1975. The behavioural significance of frill and horn morphology in ceratopsian dinosaurs. Evolution, 29:353-361.

Fastovsky, D., Weishampel, D., Watabe, M., Barsbold, R., Tsogtbaatar, K., and Narmandakh, P. 2011. A nest of Protoceratops andrewsi (Dinosauria, Ornithischia). Journal of Paleontology, 85:1035-1041.

Fromhage, L. and Kokko, H. 2014. Sexually selected traits evolve positive allometry when some matings occur irrespective of the trait. Evolution, 68:1332-1338.

Galton, P.M. 1971. A primitive dome-headed dinosaur (Ornithischia: Pachycephalosauridae) from the lower Cretaceous of England, and the function of the dome in pachycehalosaurids. Journal of Paleontology, 45:40-47.

Green, A.J. 1992. Positive allometry is likely with mate choice, competitive display and other functions. Animal Behaviour, 43:170-172.

Handa, N., Watabe, M., and Tsogtbaatar, K. 2012. New specimens of Protoceratops (Dinosauria: Neoceratopsia) from the Upper Cretaceous in Udyn Sayr,
Southern Gobi Area, Mongolia. Paleontological Research, 16:179-198.

Happ, J. 2008. An analysis of predator-prey behavior in a head-to-head encounter between Tyrannosaurus rex and Triceratops, p. 355-370. In Larson, P. and Carpenter, $\mathrm{K}$ (eds.). Tyrannosaurus rex: the Tyrant King. Indiana University Press, Blommington.

Hone, D.W.E., Farke, A.A., Watabe, M., Shigeru, S., and Tsogtbaatar, K. 2014a. A new mass mortality of juvenile Protoceratops and size-segregated aggregation behaviour in juvenile non-avian dinosaurs. PLoS ONE, 9:e113306.

Hone, D.W.E. and Faulkes, C.J. 2014. A proposed framework for establishing and evaluating hypotheses about the behaviour of extinct organisms. Journal of Zoology, 292:260-267.

Hone, D.W.E. and Naish, D. 2013. The 'species recognition hypothesis' does not explain the presence and evolution of exaggerated structures in non-avialan dinosaurs. Journal of Zoology, 290:172-180.

Hone, D.W.E., Naish, D., and Cuthill, I.C. 2012. Does mutual sexual selection explain the evolution of head crests in pterosaurs and dinosaurs? Lethaia, 45:139-156.

Hone, D.W.E. and Rauhut, O.W.M. 2010. Feeding behaviour and bone utilization by theropod dinosaurs. Lethaia, 43:232-244.

Hone, D.W.E., Sullivan, C., Zhao, Q., Wang, K., and Xu, X. 2014b. Body size distribution in a colossal hadrosaurid death assemblage from the Upper Cretaceous of Zhucheng, Shandong Province, China, p. 524531. In Eberth, D.A. and Evans, D.C. (eds.), Hadrosaurs. Indiana University Press, Bloomington.

Jerzykiewicz, T., Currie, P.J., Eberth, D.A., Johnston, P.A., and Zheng, Z.-Z. 1993. Djadokhta Formation correlative strata in Chinese Inner Mongolia: an overview of the stratigraphy, sedimentary geology, and paleontology and comparisons with the type locality in the pre-Altai Gobi. Canadian Journal of Earth Sciences, 30:2180-2190.

Knell, R.J. and Fortey, R.A. 2005. Trilobite spines and beetle horns: sexual selection in the Palaeozoic? Biology letters, 1:196-199.

Knell, R., Naish, D., Tompkins, J.L., and Hone, D.W.E. 2013a. Sexual selection in prehistoric animals: detection and implications. Trends in Ecology and Evolution, 28:38-47.

Knell, R., Naish, D., Tompkins, J.L., and Hone, D.W.E. 2013b. Is sexual selection defined by dimorphism alone? A reply to Padian and Horner. Trends in Ecology and Evolution, 28:250-251.

Knell, R.J. and Sampson, S. 2011. Bizarre structures in dinosaurs: species recognition or sexual selection? A response to Padian and Horner. Journal of Zoology, 83:18-22.

Kodric-Brown, A., Sibly, R.A., and Brown, J.H. 2006. The allometry of ornaments and weapons. Proceedings of the National Academy of Sciences, 103:87338738. 
Kraaijeveld, K., Gregurke, J., Hall, C., Komdeur, J., and Mulder, R.A. 2004. Mutual ornamentation, sexual selection, and social dominance in the black swan. Behavioural Ecology, 15:380-389.

Lauters, P., Bolotsky, Y.L., Van Itterbeeck, J., and Godefroit, P. 2008. Taphonomy and age profile of a Latest Cretaceous dinosaur bone bed in Far Eastern Russia. Palaios, 23:153-162.

Lehman, T.M. 2007. Growth and population age structure in the horned dinosaur Chasmosaurus, p. 259317. In Carpenter, K. (ed.) Horns and Beaks: Ceratopsian and Ornithopod Dinosaurs. Indiana University Press, Bloomington.

Lee, A.H. and Werning, S. 2008 Sexual maturity in growing dinosaurs does not fit reptilian growth models. Proceedings of the National Academy of Sciences, 105:582-587.

Lockley, M.G. 1991. Tracking dinosaurs: a new look at an ancient world. Cambridge University Press, Cambridge.

Lull, R.S. and Gray, S.W. 1949. Growth patterns in the Ceratopsia. American Journal of Science, 247:492503.

Maiorino, L., Farke, A.A., Kotsakis, T., and Piras, P. 2015. Males Resemble Females: Re-Evaluating Sexual Dimorphism in Protoceratops andrewsi (Neoceratopsia, Protoceratopsidae). PLoS ONE, 10:e0126464.

Mallet, J. and Joron, M. 1999. Evolution of diversity in warning color and mimicry: polymorphisms, shifting balance, and speciation. Annual Review of Ecology and Systematics, 30:201-233.

Mallon, J.C., Ryan, M.J., and Campbell, J.A. In press. Skull ontogeny in Arrhinoceratops brachyops (Ornithischia: Ceratopsiade) and other horned dinosaurs. Zoological Journal of the Linnean Society.

Maryańska, T. and Osmólska, H. 1975. Protoceratopsidae (Dinosauria) of Asia. Palaeontologia Polonica, 33:133-181.

Omland, K.E. 1996. Female mallard mating preferences for multiple male ornaments. Behavioural Ecology and Sociobiology, 39:353-360.

Padian, K. and Horner, J.R. 2011a. The evolution of 'bizarre structures' in dinosaurs: biomechanics, sexual selection, social selection or species recognition? Journal of Zoology, 283:3-17.

Padian, K. and Horner, J.R. 2011b. The definition of sexual selection and its implications for dinosaurian biology. Journal of Zoology, 283:23-27.

Padian, K. and Horner, J.R. 2013. Misconceptions of sexual selection and species recognition: a response to Knell et al. and to Mendelson and Shaw. Trends in Ecology and Evolution, 28:249-250.
Padian, K. and Horner, J.R. 2014. The species recognition hypothesis explains exaggerated structures in non-avialan dinosaurs better than sexual selection does. Comptus Rendus Palevol, 13:97-107.

Petrie, M. 1992. Are all secondary sexual display structures positively allometric, and, if so, why? Animal Behaviour, 43:173-175.

R Core Team, 2014. R: A language and environment for statistical computing. R Foundation for Statistical Computing, Vienna, Austria. http://www.R-project.org/

Sampson, S.D. 2001. Speculations on the socioecology of ceratopsid dinosaurs (Ornithischia: Neoceratopsia), p. 263-276. In Tanke, D.H. and Carpenter, K. (eds.), Mesozoic Vertebrate Life. Indiana University Press, Bloomington.

Sampson, S.D., Ryan, M.J., and Tanke, D.H. 1997. Craniofacial ontogeny in centrosaurine dinosaurs (Ornithischia: Ceratopsidae): taxonomic and behavioral implications. Zoological Journal of the Linnean Society, 121:293-337.

Schneider, C.A., Rasband, W.S., and Eliceiri, K.W. 2012. $\mathrm{NIH}$ Image to ImageJ: 25 years of image analysis. Nature Methods, 9:671-675.

Simmons, L.W. and Tomkins, J.L. 1996. Sexual selection and the allometry of earwig forceps. Evolutionary ecology, 10:97-104.

Tereschenko, V.S. and Singer, T. 2013. Structural features of neural spines of the caudal vertebrae of protoceratopoids (Ornithischia: Neoceratopsia). Paleontological Journal, 47:618-630.

Tomkins, J.L., Lebas, N.R., Witton, M.P., Martill, D.M., and Humphries, S. 2010. Positive allometry and the prehistory of sexual selection. American Naturalist, 176:141-148.

Warton, D.I., Wright, I.J., Falster, D.S., and Westoby, M. 2006. Bivariate line-fitting methods for allometry. Biological Reviews, 81:259-291.

Warton, D.I., Duursma, R.A., Falster, D.S., and Taskinen, S. 2012. smatr 3 - an R package for estimation and inference about allometric lines. Methods in Ecology and Evolution, 3:257-259.

West-Eberhard, M.J. 1983. Sexual selection, social competition, and speciation. Quarterly Review of Biology, 58:155-183.

Westoby, M. 2006. Bivariate line-fitting methods for allometry. Biological Reviews, 81:259-291.

You, H. and Dodson, P. 2004. Basal Ceratopsia, p. 478-493 In Weishampel, D.B., Dodson, P., and Osmólska, H. (eds.), The Dinosauria. University of California Press, Berkley. 
Hone, Wood, \& Knell: SeXual Selection in Ceratopsia

APPENDIX.

Table of all data used in the analyses. All measurements are in $\mathrm{mm}$. AMNH = American Museum of Natural History, New York; MPC/D = Mongolian Paleontological Centre, Ulan Baator.

\begin{tabular}{|c|c|c|c|c|c|c|c|c|c|c|c|}
\hline $\begin{array}{l}\text { Source } \\
\text { Dodson, } \\
1976\end{array}$ & $\begin{array}{c}\text { Specimen } \\
\text { AMNH }\end{array}$ & $\begin{array}{c}\text { Number } \\
6419\end{array}$ & $\begin{array}{c}\begin{array}{c}\text { Skull } \\
\text { length } \\
\text { total }\end{array} \\
115\end{array}$ & $\begin{array}{c}\begin{array}{c}\text { Skull } \\
\text { length } \\
\text { basal }\end{array} \\
76\end{array}$ & $\begin{array}{c}\begin{array}{c}\text { Frill } \\
\text { length }\end{array} \\
51.5\end{array}$ & $\begin{array}{c}\begin{array}{c}\text { Frill } \\
\text { width }\end{array} \\
67\end{array}$ & $\begin{array}{c}\text { Jugal } \\
\text { boss } \\
\text { width } \\
71\end{array}$ & $\begin{array}{c}\begin{array}{c}\text { Orbit } \\
\text { length }\end{array} \\
26.5\end{array}$ & $\begin{array}{c}\begin{array}{c}\text { Orbit } \\
\text { height }\end{array} \\
26.2\end{array}$ & $\begin{array}{c}\begin{array}{c}\text { Frill } \\
\text { minimum }\end{array} \\
\text { NA }\end{array}$ & $\begin{array}{c}\begin{array}{c}\text { Frill } \\
\text { maximum }\end{array} \\
\text { NA }\end{array}$ \\
\hline \begin{tabular}{|l} 
Dodson, \\
1976
\end{tabular} & AMNH & 6434 & 190 & 123 & 90.9 & NA & NA & 34.1 & 20 & NA & NA \\
\hline \begin{tabular}{|l|} 
Dodson, \\
1976
\end{tabular} & AMNH & 6430 & NA & 137 & NA & NA & NA & 37.1 & 30 & NA & NA \\
\hline \begin{tabular}{|l|} 
Dodson, \\
1976
\end{tabular} & AMNH & 6251 & NA & 140 & NA & NA & NA & 43.7 & 42.4 & NA & NA \\
\hline \begin{tabular}{|l} 
Dodson, \\
1976
\end{tabular} & AMNH & 6431 & 259 & 150 & 146 & 185 & 162 & 44.4 & 31.9 & NA & NA \\
\hline \begin{tabular}{|l|} 
Dodson, \\
1976 \\
\end{tabular} & AMNH & 6486 & 281 & 150 & 125 & NA & 170 & 50.7 & 35.3 & NA & NA \\
\hline \begin{tabular}{|l|} 
Dodson, \\
1976
\end{tabular} & AMNH & 6432 & 168 & 92.3 & 80.8 & NA & 200 & 43.5 & NA & NA & NA \\
\hline \begin{tabular}{|l|} 
Dodson, \\
1976
\end{tabular} & AMNH & 6428 & 170 & 90 & 57.6 & NA & NA & 32.4 & 30.3 & NA & NA \\
\hline \begin{tabular}{|l} 
Dodson, \\
1976
\end{tabular} & AMNH & 6409 & 304 & 191 & 193 & 387 & 295 & 47.6 & 55 & NA & NA \\
\hline \begin{tabular}{|l|} 
Dodson, \\
1976
\end{tabular} & AMNH & 6480 & NA & 200 & NA & NA & 225 & NA & 54 & NA & NA \\
\hline \begin{tabular}{|l|} 
Dodson, \\
1976
\end{tabular} & $\mathrm{AMNH}$ & 6444 & 340 & 210 & 191 & 374 & 325 & 51.1 & 40.6 & NA & NA \\
\hline \begin{tabular}{|l} 
Dodson, \\
1976
\end{tabular} & $\mathrm{AMNH}$ & 6485 & NA & 229 & NA & NA & NA & 52.5 & 52.7 & NA & NA \\
\hline \begin{tabular}{|l} 
Dodson, \\
1976
\end{tabular} & AMNH & 6408 & 314 & 235 & 152 & 242 & 233 & 54.4 & 54.6 & NA & NA \\
\hline \begin{tabular}{|l|} 
Dodson, \\
1976
\end{tabular} & AMNH & 6433 & 410 & 261 & 178 & NA & NA & 62.5 & 57.8 & NA & NA \\
\hline $\begin{array}{l}\text { Dodson, } \\
1976\end{array}$ & AMNH & 6429 & 408 & 169 & 208 & 333 & 399 & 70.2 & 70.8 & NA & NA \\
\hline \begin{tabular}{|l} 
Dodson, \\
1976
\end{tabular} & AMNH & 6439 & 348 & 271 & 202 & NA & NA & 62.5 & 61 & NA & NA \\
\hline \begin{tabular}{|l} 
Dodson, \\
1976
\end{tabular} & AMNH & 6441 & NA & 272 & NA & NA & NA & 58.3 & 41.5 & NA & NA \\
\hline \begin{tabular}{|l} 
Dodson, \\
1976
\end{tabular} & $\mathrm{AMNH}$ & 6477 & 490 & 303 & 265 & NA & NA & 63.8 & 59.3 & NA & NA \\
\hline \begin{tabular}{|l} 
Dodson, \\
1976
\end{tabular} & $\mathrm{AMNH}$ & 6417 & NA & NA & 182 & 375.5 & 373 & NA & 40.4 & NA & NA \\
\hline \begin{tabular}{|l} 
Dodson, \\
1976
\end{tabular} & AMNH & 6425 & 469 & 313 & 264 & 471 & 360 & 70.2 & 79 & NA & NA \\
\hline \begin{tabular}{|l|} 
Dodson, \\
1976
\end{tabular} & AMNH & 6413 & 421 & 314 & 234 & 525 & 360 & 75.7 & 58.2 & NA & NA \\
\hline \begin{tabular}{|l} 
Dodson, \\
1976
\end{tabular} & AMNH & 6414 & 461 & 341 & 249 & 490 & 400 & 77.6 & 72.6 & NA & NA \\
\hline \begin{tabular}{|l} 
Dodson, \\
1976 \\
\end{tabular} & AMNH & 6438 & NA & 352 & NA & NA & NA & 87.5 & 94 & NA & NA \\
\hline
\end{tabular}


APPENDIX (continued).

\begin{tabular}{|c|c|c|c|c|c|c|c|c|c|c|c|}
\hline $\begin{array}{l}\text { Source } \\
\text { Dodson, } \\
1976\end{array}$ & $\begin{array}{c}\text { Specimen } \\
\text { AMNH }\end{array}$ & $\begin{array}{c}\text { Number } \\
6466\end{array}$ & $\begin{array}{c}\text { Skull } \\
\text { length } \\
\text { total } \\
491\end{array}$ & \begin{tabular}{|c}
$\begin{array}{c}\text { Skull } \\
\text { length } \\
\text { basal }\end{array}$ \\
357
\end{tabular} & $\begin{array}{c}\begin{array}{c}\text { Frill } \\
\text { length }\end{array} \\
262\end{array}$ & $\begin{array}{c}\begin{array}{c}\text { Frill } \\
\text { width }\end{array} \\
465\end{array}$ & 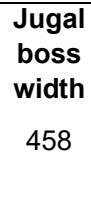 & $\begin{array}{c}\begin{array}{c}\text { Orbit } \\
\text { length }\end{array} \\
78.3\end{array}$ & $\begin{array}{c}\begin{array}{c}\text { Orbit } \\
\text { height }\end{array} \\
75\end{array}$ & $\begin{array}{c}\begin{array}{c}\text { Frill } \\
\text { minimum }\end{array} \\
\text { NA }\end{array}$ & $\begin{array}{c}\begin{array}{c}\text { Frill } \\
\text { maximum }\end{array} \\
\text { NA }\end{array}$ \\
\hline \begin{tabular}{|l|} 
Dodson, \\
1976
\end{tabular} & $\mathrm{AMNH}$ & 6467 & 515 & 285 & 257.5 & 445 & 358 & 61.1 & 61.3 & $\mathrm{NA}$ & NA \\
\hline $\begin{array}{l}\text { Handa et } \\
\text { al., } 2012\end{array}$ & MPC/D & $100 / 539$ & NA & 185.5 & NA & NA & 191.5 & 53 & 48 & NA & NA \\
\hline $\begin{array}{l}\text { Hone et al., } \\
2014 a\end{array}$ & MPC/D & $100 / 534$ & 285.5 & 145.5 & 138.5 & 240 & 159 & 38.5 & 47 & NA & NA \\
\hline $\begin{array}{l}\text { Hone et al., } \\
2014 a\end{array}$ & MPC/D & $100 / 526$ B & 128 & 79 & 49 & 52.5 & 44 & 31 & 23 & 23 & 53.5 \\
\hline $\begin{array}{l}\text { Hone et al., } \\
2014 a\end{array}$ & MPC/D & $100 / 526 \mathrm{C}$ & 125 & 91.5 & 33.5 & NA & NA & 25.5 & 28.5 & 24 & 53 \\
\hline $\begin{array}{l}\text { Fastovsky } \\
\text { et al., } 2011\end{array}$ & MPC/D & $100 / 530 a$ & 41.4 & 26 & 15.5 & 22 & 22 & 14.5 & NA & 13 & 16 \\
\hline $\begin{array}{l}\text { Fastovsky } \\
\text { et al., } 2011 \\
\end{array}$ & MPC/D & $100 / 530 \mathrm{~b}$ & 41 & 23.5 & 17 & 25 & 26 & 11 & NA & 14 & 17.5 \\
\hline $\begin{array}{l}\text { Fastovsky } \\
\text { et al., } 2011\end{array}$ & MPC/D & $100 / 530 \mathrm{c}$ & 35 & NA & 15.5 & 19 & NA & 10.5 & NA & 14 & 18 \\
\hline $\begin{array}{l}\text { Fastovsky } \\
\text { et al., } 2011\end{array}$ & MPC/D & $100 / 530 \mathrm{~d}$ & 46.5 & 29.5 & 16 & 24 & NA & 14 & 10.5 & 14 & 17 \\
\hline $\begin{array}{l}\text { Fastovsky } \\
\text { et al., } 2011\end{array}$ & MPC/D & $100 / 530 \mathrm{e}$ & 39.5 & 28 & 12 & 23.5 & NA & 12.5 & 9.5 & 13 & 10 \\
\hline $\begin{array}{l}\text { Fastovsky } \\
\text { et al., } 2011\end{array}$ & MPC/D & $100 / 530 \mathrm{f}$ & 51 & 33.5 & 16.5 & 25.5 & 41 & 17 & 11 & 16.5 & 13.5 \\
\hline $\begin{array}{l}\text { Fastovsky } \\
\text { et al., } 2011\end{array}$ & MPC/D & $100 / 530 \mathrm{~g}$ & 40.5 & 32 & 12 & 21 & NA & 15 & 10 & 13.5 & 15 \\
\hline $\begin{array}{l}\text { Fastovsky } \\
\text { et al., } 2011\end{array}$ & MPC/D & $100 / 530 \mathrm{~h}$ & 35 & 27 & 12 & 22.5 & NA & 12 & 8.5 & 12.5 & 13.5 \\
\hline
\end{tabular}

